\title{
The Relationship Between Polymorphisms of FTO Gene and Type 2 Diabetes Mellitus
}

\author{
Sayed Alireza Mirsane, ${ }^{1,2,}$, Shima Shafagh, ${ }^{3}$ and Nasrin Oraei ${ }^{4}$ \\ ${ }^{1}$ Genetic Sciences Student and Researcher, University Complex, Qom, IR Iran \\ ${ }^{2}$ Surgical Technologist, Kashan University of Medical Sciences, Kashan, IR Iran \\ ${ }^{3}$ General Surgery Specialist, Medical School, Kashan University of Medical Sciences, Kashan, IR Iran \\ ${ }^{4}$ Lecturer of Education Office, Esfahan, IR Iran \\ "Corresponding author: Sayed Alireza Mirsane, Genetic Sciences Student and Researcher, University Complex, 15 Khordad Blvd, Qom, IR Iran. E-mail: \\ alireza.seyed70@gmail.com
}

Received 2016 September 03; Revised 2016 November 07; Accepted 2016 November 08.

Keywords: Type 2 Diabetes Mellitus, FTO Gene, Polymorphism, Genetics

\section{Dear Editor,}

Type 2 diabetes mellitus (T2DM) is one of the important reasons of hyperglycemia and considering the prevalence of T2DM in different populations is a notable point. The recent T2DM estimates demonstrated the large T2DM burden in the developing countries (1). Researchers also indicated that weight regulation (2) and genes (3) are associated with T2DM. On the other hand, the protein linked to fat mass and obesity, also known as FTO, is an enzyme encoded by the FTO gene and plays a significant role in the in the body weight regulation (4). The current study aimed to detect the relationship between FTO gene polymorphism and T2DM. Several studies are conducted on the association of FTO gene polymorphisms and T2DM. Scuteri et al. (3) explained that rs9930506 polymorphism of FTO gene can be as a risk factor for T2DM, since it is associated with obesity. Horikoshi et al. (5) in Japan, in their study performed on 864 individuals without diabetes and 864 individuals with T2DM stated that polymorphism of rs8050136 had significant association with T2DM. Another study that considered dependence of rs16953002 polymorphism FTO gene and T2DM in urban population of Yazd in Iran indicated that the mentioned polymorphism may be related to T2DM (6). Song et al. (7) explained a very strong relationship between rs9939609 polymorphism of FTO gene inter intron 1 and T2DM. Ramya et al. (8) stated that polymorphism of rs1588413 located in intron 8 had meaningful relationship with T2DM in the Indian population. The results of another study showed relationship among T2DM and rs17817449 polymorphism in Sudanese population (9). As well as, in other research was suggested that rs17817449 polymorphism has association with T2DM (10).

According to the results, polymorphisms of FTO gene may be associated with T2DM, since several studies are based on the role of FTO gene polymorphisms in the pathogenesis of T2DM. This subject needs multiple studies; hence, it is advised to conduct more studies to obtain exact and comprehensive results.

\section{References}

1. Yang L, Shao J, Bian Y, Wu H, Shi L, Zeng L, et al. Prevalence of type 2 diabetes mellitus among inland residents in China (2000-2014): A metaanalysis. J Diabetes Investig. 2016;7(6):845-52. doi: 10.1111/jdi.12514. [PubMed: 27181391].

2. O'Neil PM, Miller-Kovach K, Tuerk PW, Becker LE, Wadden TA, Fujioka $\mathrm{K}$, et al. Randomized controlled trial of a nationally available weight control program tailored for adults with type 2 diabetes. Obesity (Silver Spring). 2016;24(11):2269-77. doi: 10.1002/oby.21616. [PubMed: 27804264].

3. Scuteri A, Sanna S, Chen WM, Uda M, Albai G, Strait J, et al. Genomewide association scan shows genetic variants in the FTO gene are associated with obesity-related traits. PLoS Genet. 2007;3(7):115. doi: 10.1371/journal.pgen.0030115. [PubMed: 17658951].

4. Loos RJ, Yeo GS. The bigger picture of FTO: the first GWASidentified obesity gene. Nat Rev Endocrinol. 2014;10(1):51-61. doi: 10.1038/nrendo.2013.227. [PubMed: 24247219].

5. Horikoshi M, Hara K, Ito C, Shojima N, Nagai R, Ueki K, et al. Variations in the HHEX gene are associated with increased risk of type 2 diabetes in the Japanese population. Diabetologia. 2007;50(12):24616. doi: 10.1007/s00125-007-0827-5. [PubMed: 17928989].

6. Bakhshi Ganje M, Sheykhha MH, Farashahi E, Mohammadzade M. Association of rs16953002 FTO Gene Polymorphism with Type 2 Diabetes and Obesity.J Fasa Univ Med Sci. 2016;6(1):27-34.

7. Song Y, You NC, Hsu YH, Howard BV, Langer RD, Manson JE, et al. FTO polymorphisms are associated with obesity but not diabetes risk in postmenopausal women. Obesity (Silver Spring). 2008;16(11):2472-80. doi: 10.1038/oby.2008.408. [PubMed: 18787525].

8. Ramya K, Radha V, Ghosh S, Majumder PP, Mohan V. Genetic variations in the FTO gene are associated with type 2 diabetes and obesity in south Indians (CURES-79). Diabetes Technol Ther. 2011;13(1):33-42. doi: 10.1089/dia.2010.0071. [PubMed: 21175269].

9. Niyazy MM. The Role of FAT MASS and Obesity Association Locus" Fto" Gene Polymorphism in Susceptibility to Development of Type 2 Diabetes and Obesity in Selected Sudanese Population Sudan: University of Khartoum; 2015. Available from: http://khartoumspace.uofk.edu/ $123456789 / 17195$. 
10. Prakash J, Srivastava N, Awasthi S, Agarwal CG, Natu SM, Rajpal N, et al. Association of FTO rs17817449 SNP with obesity and associated physiological parameters in a north Indian population. Ann Hum
Biol. 2011;38(6):760-3. doi: 10.3109/03014460.2011.614278. [PubMed: 21919686]. 